\title{
Congenital Postural Scoliosis
}

\author{
Sir DENIS BROWNE,* K.C.V.o., F.R.C.S., F.R.A.C.S.(HON.)
}

[With Special Plate]

Brit. med. F., 1965, 2, 565-566

A short time ago it was extremely rare for a simple congenital dislocation of the hip to be diagnosed at birth, when treatment is easiest and most successful. It is now being increasingly realized that diagnosis is not difficult provided that those in charge of the newborn know what to look for. It is the contention of this paper that a similar situation exists in regard to another congenital displacement of the bones-that which ends as the crippling condition of "idiopathic scoliosis."

In discussing this subject I assume that the distinction I have been making for many years between malposition and abnormal pressure, spatial and hydrostatic, during intrauterine life is understood (Browne, 1955; 1956). This need not mean that my hypothesis is accepted, but merely that the argument is grasped.

The condition with which this paper is mainly concerned is a result of simple malposition: a baby normal in every other way has been lying in utero with the spine bent to one side, and on emerging tends to keep the same bend (Special Plate, Fig. 1).

In the other type the baby has been subject to undue spatial pressure, or, to put it more simply, has been squashed, to become what I hope is now being recognized as a "compression" baby (S.P. Figs. 7 and 8). In the simple " congenital postural scoliosis" the baby lies in a position that any normal child can assume ; the essential abnormality being that he cannot be got to take up the corresponding opposite curve. In "compression scoliosis" there is not merely a wrong posture but a marked and obvious deformity, which can rarely be overlooked at birth and which is most intractable. The postural scoliosis, on the other hand, is invariably (in my experience) overlooked at birth, and is easy to correct if treatment is early and efficient. The analogy with congenital dislocation of the hip is close. When the hips are dislocated in a "compression baby" the malformation is very easy to diagnose and very difficult to treat. But when the intrauterine conditions have been normal the dislocation is found only when it is deliberately sought for, and treatment is easy and satisfactory when begun in the first days of life. Another resemblance between the two conditions is in the tendency of the slighter degrees of both to spontaneous cure. There seems no doubt that many unstable hips, in which the head of the femur snaps in and out of a shallow acetabulum immediately after birth, become stable without treatment; and the same holds for minor degrees of scoliosis in otherwise normal babies. But, as it is impossible to say which hips will become stable and which will dislocate permanently, it is now the approved practice to treat them all in simple abduction splints. I consider the same course should be followed in all cases of scoliosis for exactly the same reasons.

\section{Diagnosis}

\section{Listening to the Mother}

Admittedly mothers differ in intelligence, and it is possible for advanced scoliosis to be overlooked in the most amazing * Emeritus Surgeon, the Hospital for Sick Children, Great Ormond
Street, London. way by all concerned. But on the other hand babies are brought up for consultation in the first few months with some variant of the accurate clinical description: "He always screws round one way." It is part of the present picture that only too often such a mother is told not to be fussy.

\section{Playing with the Baby}

The newborn baby will squirm when tickled in the ribs while lying horizontally, bending towards the side stimulated. If he will not do this equally to either side the spine is under suspicion. In older children the aid of the mother should be sought, and she should try to get the child to bend round to either side after something that attracts him.

\section{Noting Wrinkles}

A sign of fixed scoliosis which becomes more marked with age is the presence of permanent wrinkles on the concave side of the chest, rather like the ones which adults have at the corners of their eyes.

\section{The " Triptych" Radiograph (S.P. Fig. 2)}

This final proof is a picture taken of the spine with the baby lying at ease, and then flanked by two others with the spine bent, by gripping shoulders and pelvis, as far in either direction as can be done without discomfort. When a scoliosis is present the spine bends easily round to exaggerate the bend shown in the central film, while in the opposite direction the bending occurs above and below the scoliotic area, which remains hardly changed.

\section{Progress}

If the condition is untreated various factors combine to cause the progression which is the essential feature of the deformity:

1. The very high muscular tone characteristic of the normal newborn baby. This is noticeable in the illustrations (S.P. Fig. 4), and the muscles on the concave side have an obvious mechanical advantage over those on the convex.

2. The pull of gravitation on the body when the child sits, stands, and walks.

3. The increased leverage employed by both these forces as the spine bends further and further, so that progression tends to accelerate. As I have said, in the early stages of this condition correction is not difficult, but there is a "point of no return" after which the dislocation of the joints of the vertebrae has become so fixed that no known device will serve to correct it (S.P. Figs. 5 and 6), still less to give the necessary reversal or over-correction which is essential.

It is impossible to give an exact age for the change from the correctable to the intractable, but it occurs soon after the child has learnt to walk, and so emphasizes the importance of early diagnosis and treatment. 
As I have said, some scolioses of infancy correct themselves spontaneously; I have made no observations on this point myself, never having considered it justifiable to leave a child untreated in order to obtain useless knowledge of percentages of cures and disasters. In any event I am not much impressed by the published statistics on this point in the absence of any distinction between the two types I have described, and of any knowledge of the extent of the deformity as demonstrated by the triptych radiograph. The need for this kind of radiograph is shown in the statement of Scott (1956) that $80 \%$ of babies have scoliosis. To add to this vagueness about diagnosis there is the invariable habit of writers on the subject to speak of the scoliosis "beginning" at a certain age, when what is really meant is "being noticed." The process of worsening is well recognized, but the process is not traced back in the other direction to a normal spine, and if my ideas are correct this vill be for ever impossible in these cases.

The alleged frequency of spontaneous correction is used by some surgeons as a reason for refusing to treat any scolioses in infants, this attitude being reinforced by the absence of any classical splint to control the curve. It has been explained to me that if all are treated then some will be treated unnecessarily. Apart from the analogy already made with unstable hips I would cite appendicitis, most cases of which would undoubtedly recover if simply left quiet ; but the difference between a death rate of $10 \%$ or so and one of a twentieth of that figure is generally reckoned to be worth the trouble of appendicectomy.

Leaving any ethical problems out of consideration, an awkward situation can arise when a mother who has been refused treatment for a baby which turns out to be one of the unlucky ones meets a mother of a treated child who has a straight back.

\section{Treatment}

Treatment turns on three main principles:

\section{Reversal of the Deformity}

This can be done by my scoliosis splint ${ }^{1}$ (S.P. Fig. 3) and should be continuous, the baby being kept in it for 24 hours a day except for removal for washing and exercises.

\section{Controlled Movement}

This means that all muscular activities are encouraged with the exception of those which perpetuate or worsen the deformity. My splint consists of a flat aluminium base with, on one side of it, a curved wall of the same metal perforated by two holes of a size to take an arm up to the shoulder. It is covered with sponge-rubber fabric, and a broad padded band is fastened with a buckle through the vertical wall, so that when it is tightened the baby's spine is pulled into its curve. According to the direction of the scoliosis the child has the left arm or the right through the arm-hole in the wall. Occasionally it is necessary with very active and ingenious children to add a strap through the base over the shoulder on the free side to prevent a rotation of the body that enables partial escape. The child is kept in this splint till he will turn equally easily and voluntarily to either side, and then its use is progressively reduced to sleeping times only, finally being cautiously given

\footnotetext{
${ }^{1}$ Obtainable from Messrs. Pryor and Howard, Willow Lane, Mitcham.
}

up entirely. It is impossible to say how long this will take, but it is usually from six to 12 months, depending on such factors as the severity of the bend, the age of beginning treatment, and the intelligence and conscientiousness of the parents.

\section{Stimulation of Voluntary Movements}

This can be done by exercises which are carried out by plaving on the baby's natural responses to position-for instance, if the head is allowed to hang downwards his reaction is to raise it.

\section{Treatment of Late Cases}

I think it might be possible to reverse or stabilize such cases as those shown in S.P. Fig. 5, but this would need the working out of new methods to reverse the deformity and allow controlled movement. The Milwaukee brace (James et al., 1959), though it may slow down the progress of the scoliosis, does not fulfil the primary condition of reversing it, and it is a great hindrance to the natural activity of a child. I have reason to think that free movement in a reversed spinal curve could be obtained by a yoke round the shoulders, connected by a strap on one side to a corresponding grip on the pelvis. This would allow free movement in the playing of games and consequently the gaining of muscle balance, probably by the establishment of compensating curves to the original one. As all my work and research on this group of cases came suddenly to an end under the retiring-age regulations of the National Health Service I am unable to pursue this idea, but I should be most willing to collaborate with anyone of a suitable age with suitable cases.

\section{Summary}

It is suggested that:

(1) Under the name of "idiopathic scoliosis" two different conditions are being confused, both due to mechanical factors in utero.

The one condition is congenital postural scoliosis, which can be diagnosed at the most favourable age only by special investigations. When the condition is diagnosed early correction is easy, but after a certain age it becomes impossible by any methods now known. There is a tendency to spontaneous correction in an uncertain proportion of cases.

The other condition is congenital compression scoliosis, in which the deformity is obvious at birth and correction extremely difficult. There is no tendency to spontaneous correction.

(2) It is argued that all babies should be examined at birth for the postural type of scoliosis, and instructions for this are given.

(3) A device for correcting the spinal bend is described, and instructions for its use given.

Special Plate Figs. 2 and 4 are reproduced by courtesy of $\mathrm{Mr}$. Harold Nixon.

\section{REFERENCES}

Browne, Denis (1955). Arch. Dis. Childh., 30, 37.

Browne, (15 56). Proc. roy. Soc. Med., 49, 395. James. J. I. P., Lloyd-R

Scott, J. C. (1956). Proc. roy. Soc. Med., 49, 398. 
SIR DENIS BROWNE: CONGENITAL POSTURAL SCOLIOSIS

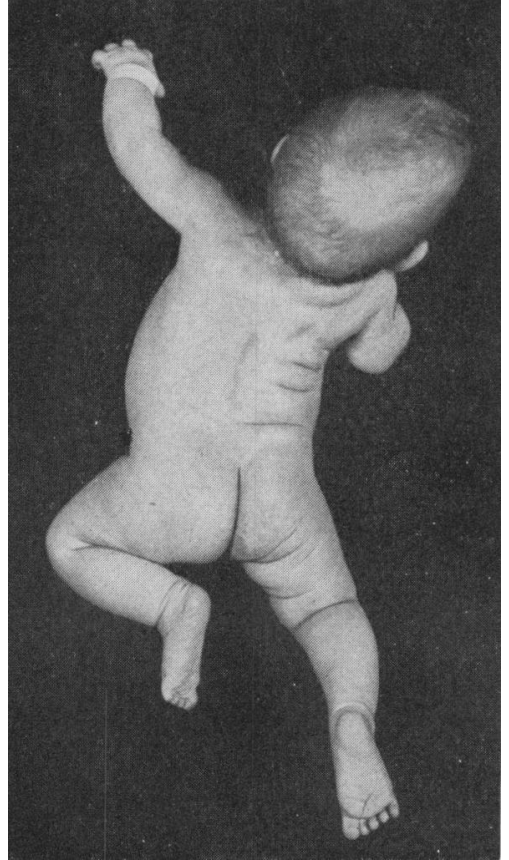

Fig. 1

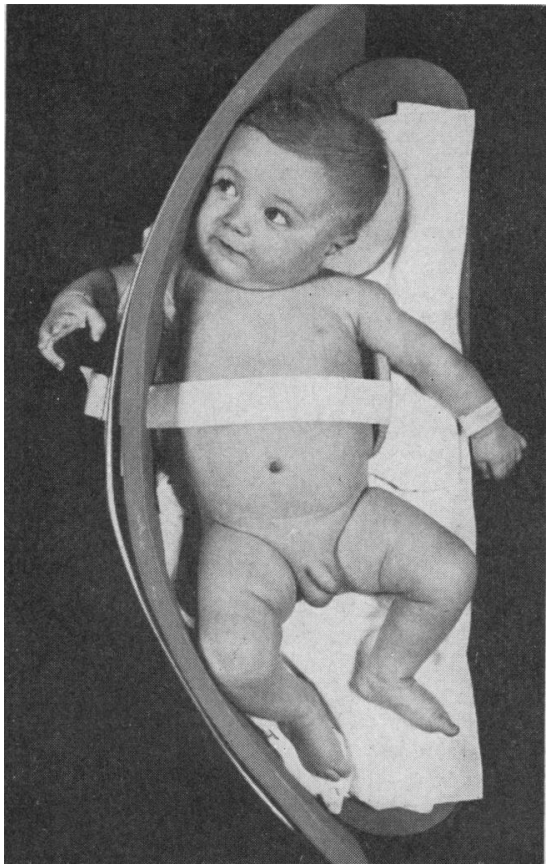

Fig. 3
FIG. 1.-Congenital postural scoliosis. Note spasmodic action of muscles on concave side, and skin wrinkles.

FIG. $2 a$ and $b .-$ Radiographs of congenital postural scoliosis, consisting of triptych radiograph, with (at right) the result of six months in the splint.

Fig. 3.-Child shown in Fig. 1 in splint, soon after first application. The pull can be made more forcible later to increase reversal of original curve.

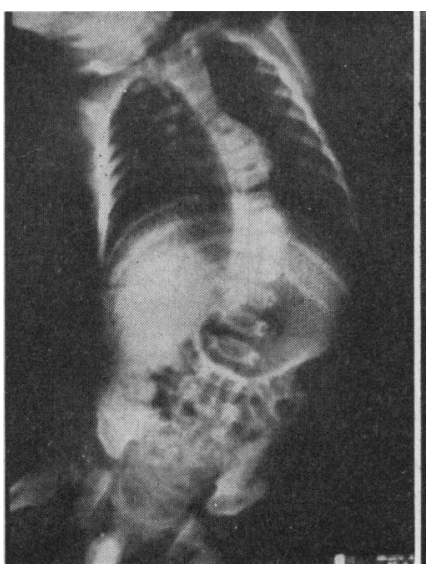

FIG. $2 a$
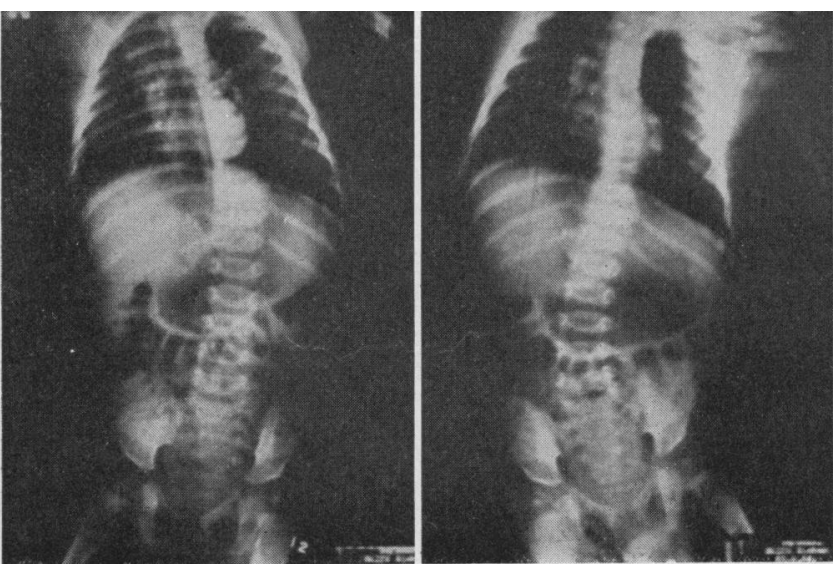

FIG. 4.-A series of children with congenital postural scoliosis photographed on their first appearance at hospital. They were all treated as recommended, and all now have straight backs. The one in the top lefthand corner was one of two sisters, the other hand corner was one of two sisters, the other having such an apparently slight curve that she was not sent up for treatment. This
untreated child has now marked and increasing "idiopathic" scoliosis.

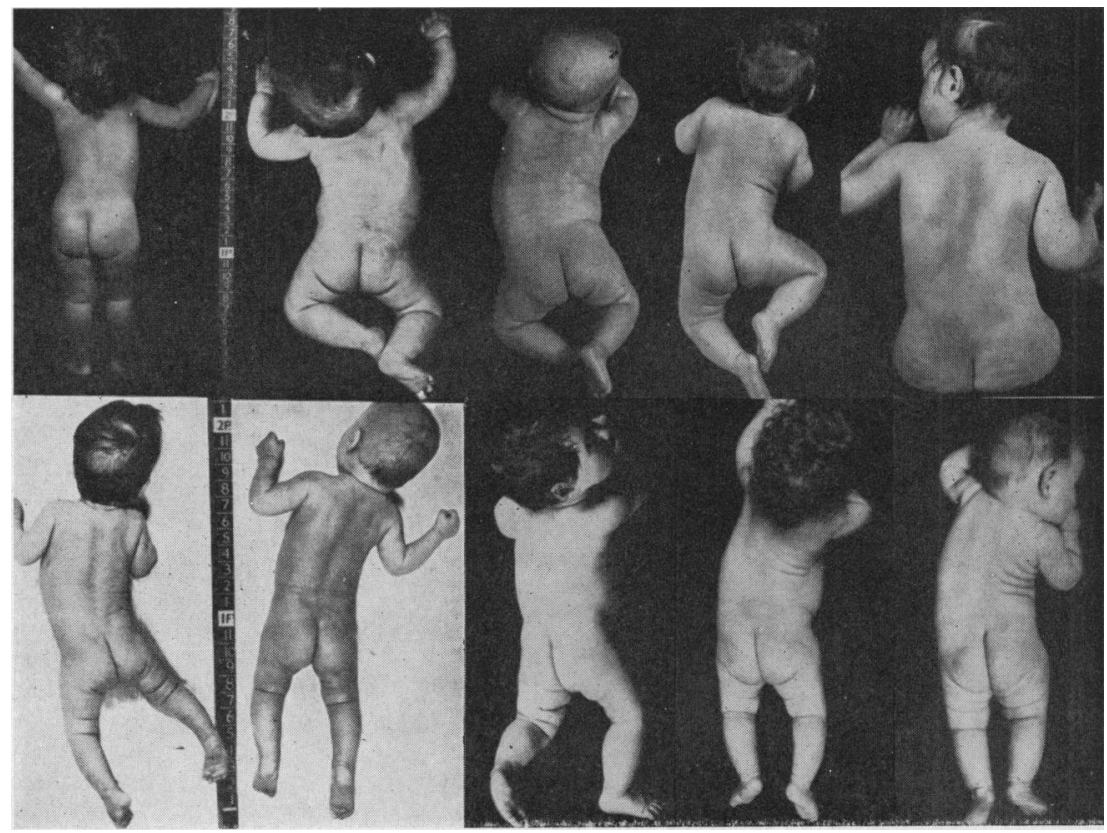


SIR DENIS BROWNE: CONGENITAL POSTURAL SCOLIOSIS

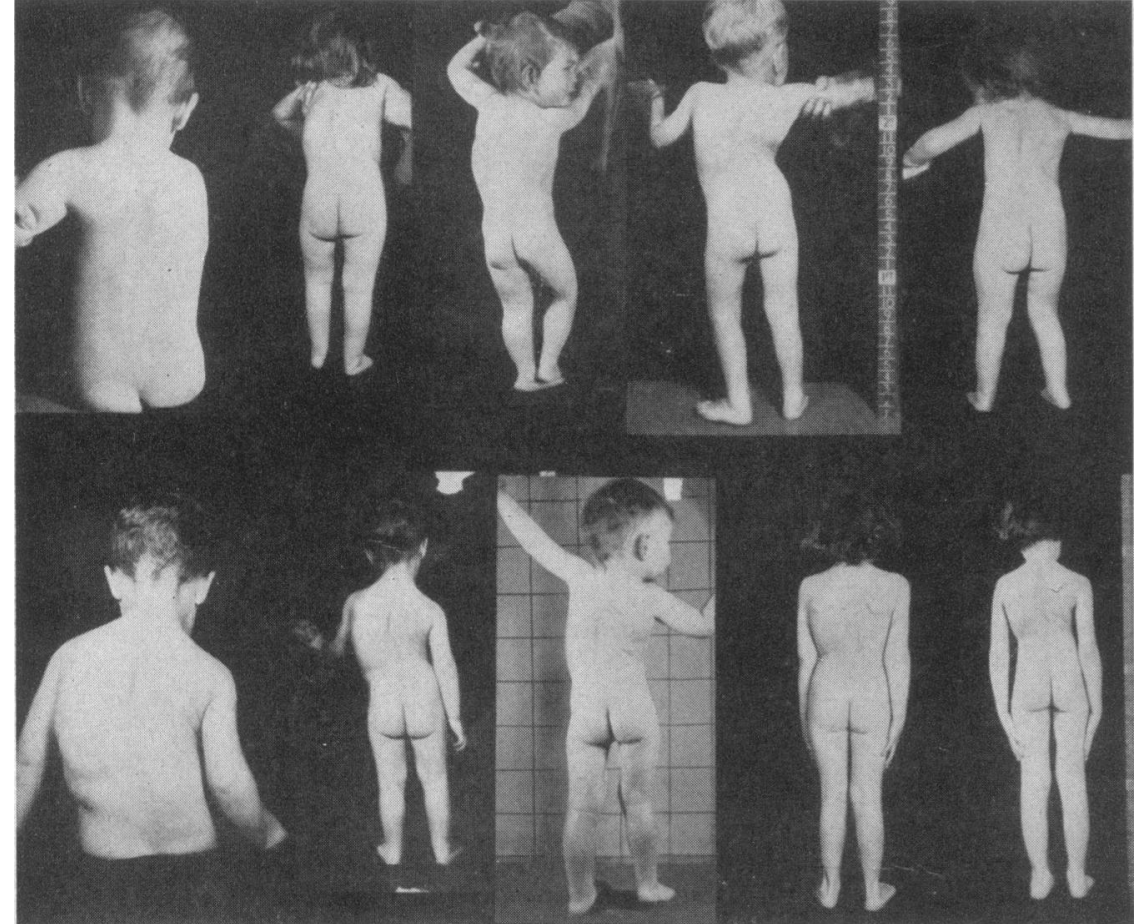

FIG. 5.- Series of cases, photographed at their first appearance, all having passed the "point of no return." The scoliosis of all these is increasing in spite of treatment.

Fig. 6. - Congenital postural aged 14.

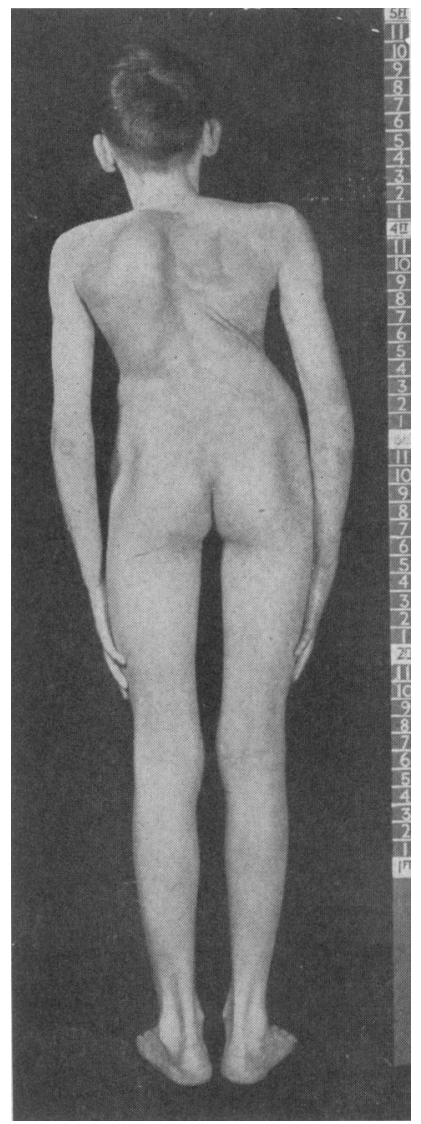

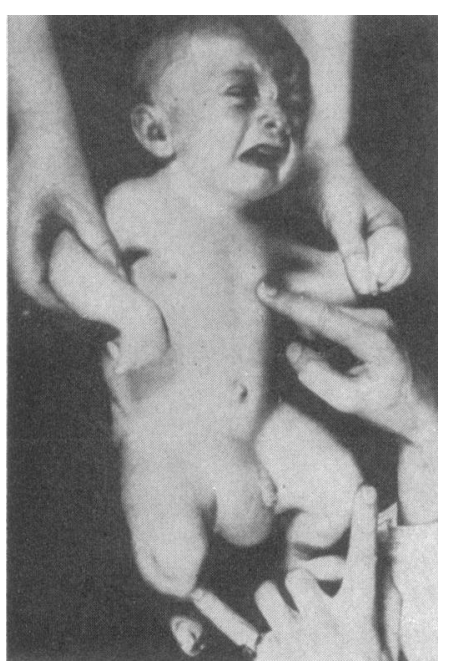

$\boldsymbol{a}$

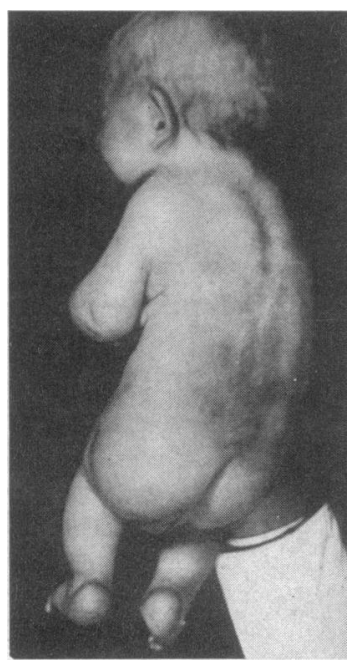

b

Fig. $7 a, b$, and $c$.-Congenital compression scoliosis, child aged 3 months. The back was extremely rigid, and the child died shortly afterwards of respiratory disease.

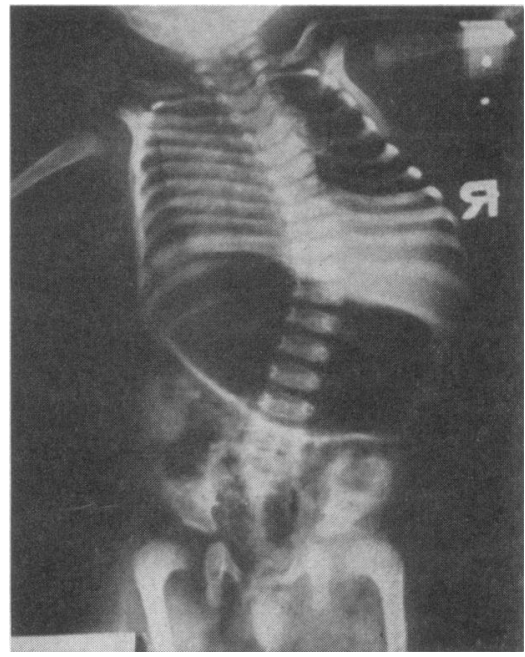

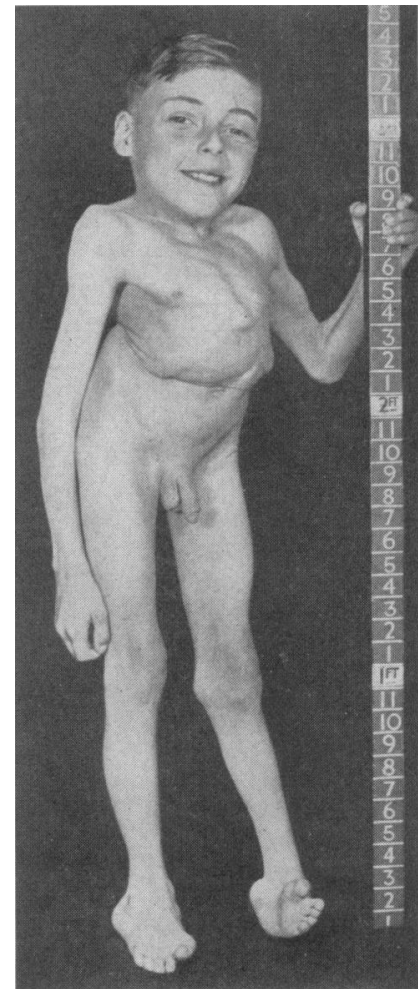

FIG. 8.-Congenital compression scoliosis, boy aged 10. Note moulding of left foot, of the same type as moulding of spine. 